\title{
Pearls \& Oy-sters: The dangers of PRES
}

\section{An atypical case with life-threatening presentation} Christina Catherine, MD, PhD, Claire Yanta, MD, Aisha R. Saand, MD, Madison Pilato, MD,
and Sherry H.-Y. Chou, MD, MSc

Neurology ${ }^{\circledR}$ 2019;92:e282-e285. doi:10.1212/WNL.0000000000006775

\section{Pearls}

- The presentation of posterior reversible encephalopathy syndrome (PRES) can be highly variable, with headaches and seizures being common.

- $\quad$ PRES should be considered even if imaging findings are in an atypical location such as the brainstem or diencephalon.

- $\quad$ PRES may present with life-threatening acute obstructive hydrocephalus, which requires prompt treatment.

\section{Oy-sters}

- Prognosis of PRES is usually good, especially if the cause can be identified and treated.

- PRES can recur, or it can present with ischemic events or intracranial hemorrhage.

- Immunosuppressant medications can be associated with PRES. Changing to a nonoffending agent is necessary for reversal of PRES.

\section{Case report}

A 38-year-old woman with a medical history of diffuse scleroderma, severe vasculopathy, and interstitial lung disease treated with double lung transplant on tacrolimus immunosuppression presented to the emergency department with the "worst headache of her life." She had just been discharged from the hospital earlier that day following treatment for Clostridium difficileassociated diarrhea, Aspergillus pneumonia, and mild antibody-mediated transplant rejection treated with rituximab. Headache was associated with dizziness and feeling “cross-eyed.” Initial neurologic examination showed normal mental status, paralysis of upgaze, but no other focal neurologic deficits. Admission blood pressure (BP) was 167/98 mm Hg (range 103-174 mm $\mathrm{Hg} / 52-118 \mathrm{~mm} \mathrm{Hg}$ during 24 hours pre/postadmission). Head CT without contrast did not demonstrate an intracranial hemorrhage or other acute intracranial process. Given the benign neurologic examination, she was treated with IV prochlorperazine and diphenhydramine for suspected migraine headache before being observed overnight in the emergency department. On re-evaluation several hours later, she was found to be minimally responsive with an episode of teeth grinding and convulsions followed by emesis that was concerning for a seizure. On neurologic examination, she was comatose with flexor posturing, left gaze deviation, and unreactive pupils; $3+$ reflexes were noted throughout. An emergent MRI demonstrated bilateral vasogenic edema in the thalami, midbrain, and dorsal pons, as well as acute hydrocephalus likely secondary to edema and mass effect causing obstruction to CSF flow at the level of the third ventricle and cerebral aqueduct (figure $1, \mathrm{~A}-\mathrm{D}$ ).

Following MRI, the patient was immediately given IV dexamethasone for the edema and lorazepam for possible status epilepticus. She was loaded with phenytoin plus additional lorazepam given concern for ongoing seizure activity. Initial EEG after being loaded with antiepileptics noted generalized slowing with $1-3 \mathrm{~Hz}$ polymorphic delta intermixed with $5-7 \mathrm{~Hz}$ theta slowing. A repeat head CT approximately 4 hours later showed expanding ventricles with prominent dilation of the temporal horns bilaterally and obliteration of the basal cisterns

\author{
Correspondence \\ Dr. Chou \\ chouh@upmc.edu
}

From the Department of Neurology (C.C., C.Y., M.P.), University of Pittsburgh Medical Center; and Departments of Critical Care Medicine (A.R.S., S.H.-Y.C.), Neurology, and Neurosurgery (S.H.-Y.C.), University of Pittsburgh School of Medicine, PA.

Go to Neurology.org/N for full disclosures. Funding information and disclosures deemed relevant by the authors, if any, are provided at the end of the article. 


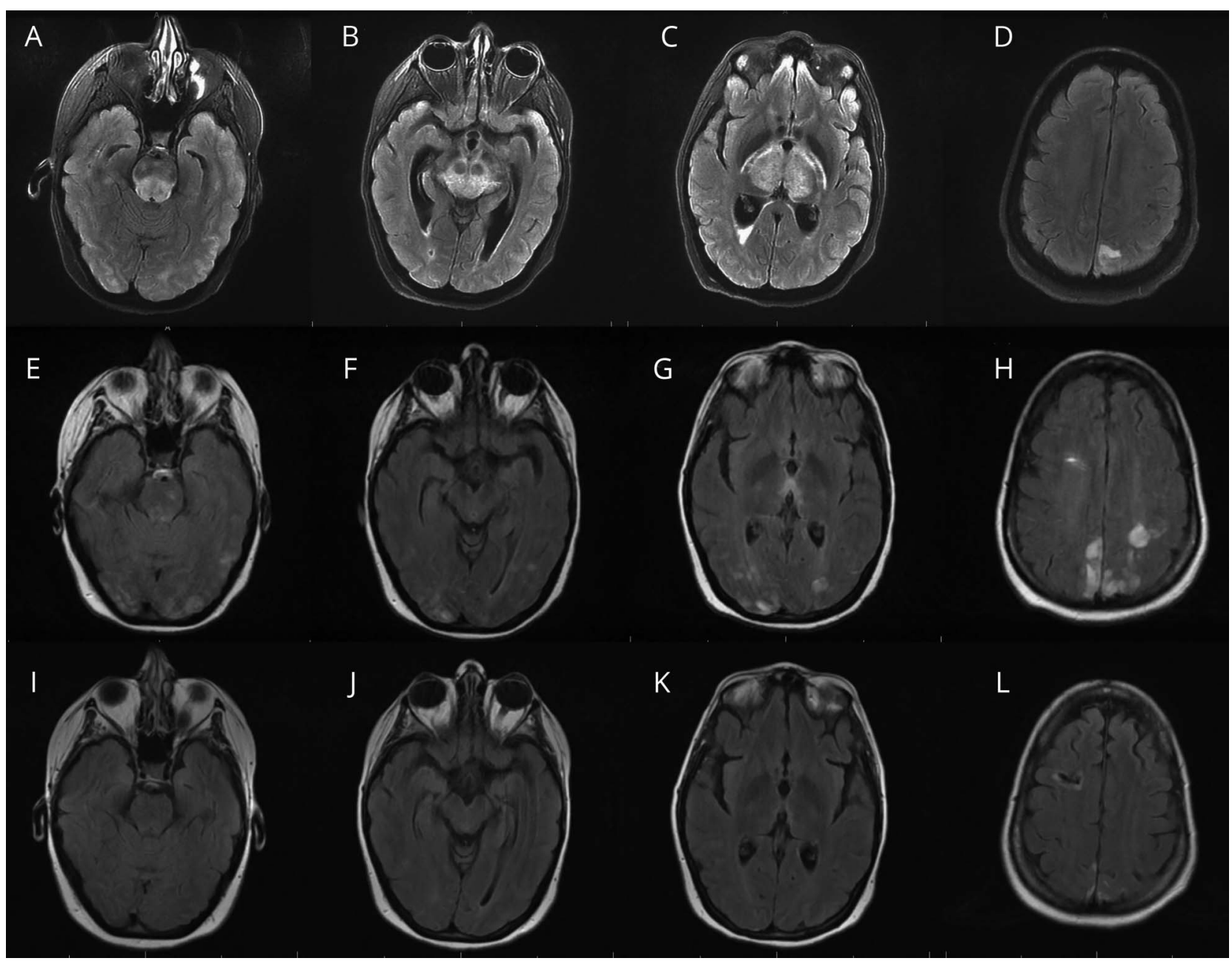

(A-D) Initial MRI shows T2 fluid-attenuated inversion recovery (FLAIR) hyperintensities in the pons, midbrain, bilateral thalami, bilateral basal ganglia, and left occipital lobe. (E-H) MRI at presentation of repeat PRES 1 month following initial presentation shows T2 FLAIR hyperintensities in the pons, midbrain, bilateral thalami, bilateral basal ganglia, and left occipital lobe. Note that an interim MRI brain between these images was notable only for a small residual hemorrhage in the right frontal lobe along the external ventricular drain (EVD) tract. (I-L) Follow-up MRI brain (T2 FLAIR) 1 year following last occurrence of PRES. Note that the only residual abnormality is hemosiderin deposition located in the prior EVD tract that was complicated by hemorrhage.

concerning for impending herniation. Angiogram was negative for cerebral venous sinus thrombosis. An emergent external ventricular drain (EVD) was placed with opening pressure of $15 \mathrm{~mm} \mathrm{Hg}$. Prior to EVD placement, she was comatose, pupils were equal but unreactive, corneal and gag reflexes were present, she withdrew to noxious stimuli in her upper but not lower extremities, and tone was increased in all extremities. She was transferred to the neurologic intensive care unit for further management. Admission laboratory studies were pertinent for $\mathrm{Na} 130 \mathrm{mmol} / \mathrm{L}$, blood urea nitrogen $31 \mathrm{mg} / \mathrm{dL}$, ammonia $29 \mu \mathrm{mol} / \mathrm{L}$, white blood cells (WBCs) $2.7 \times 10^{9} / \mathrm{L}$, and a negative urine drug screen. Initial CSF drawn after EVD placement showed 0 WBCs, 6,875 red blood cells, 80 glucose, 91 protein, and slight xanthochromia.

Differential diagnosis included infectious, autoimmune, and paraneoplastic rhomboencephalitis, cerebral venous sinus thrombosis, and atypical presentation of PRES due to immunosuppressant medication. Given her immunocompromised state, the patient was started on IV sulfamethoxazole/trimethoprim for possible Listeria rhomboencephalitis, IV ceftriaxone for possible CNS Lyme, and IV ganciclovir for broad antiviral coverage. High-dose dexamethasone was continued for cerebral edema. CSF studies were negative for Listeria, cytomegalovirus, herpes simplex virus 1/2, Epstein-Barr virus, and West Nile virus. Rheumatologic workup, as well as a full workup for paraneoplastic disorders including NMDA and GABA-B antibodies, was negative.

The neurologic examination improved tremendously over the 36 hours following EVD placement (average output $20 \mathrm{~mL} / \mathrm{h}$ ). The patient was changed from tacrolimus to everolimus for immunosuppression. Following this medication change, she became alert, was oriented to herself, and was able to follow simple commands with antigravity movements 
in all extremities and intact sensation. Two days after initial presentation, she was extubated successfully and was close to her neurologic baseline except for mild delirium. EVD was removed on day 6 after placement. Repeat MRI showed substantial improvement in the previously involved brainstem areas (figure 1, E-H). The patient was discharged to an acute rehabilitation facility about 2 weeks from symptom onset without further complications and continued on everolimus and cyclosporine for transplant immunosuppression.

Approximately 1 month after hospital discharge, the patient again presented with altered mental status. Examination was notable for stupor, no spontaneous movement of extremities, and minimal withdrawal to noxious stimuli. Emergent MRI demonstrated posterior-predominant subcortical and cortical fluid-attenuated inversion recovery (FLAIR) changes concerning for PRES (figure 1, E-H). Immediately following MRI, she had a generalized tonic-clonic (GTC) seizure and was given $8 \mathrm{mg}$ lorazepam and $5 \mathrm{mg}$ midazolam. She had another GTC several hours later and was noted to be in status epilepticus. Her levetiracetam dosing was increased to $1,000 \mathrm{mg}$ bid and lacosamide $100 \mathrm{mg}$ was started without improvement. She was then loaded with phenytoin $1 \mathrm{~g}$ and started on oxcarbazepine. Cyclosporine was discontinued, while everolimus and prednisone were continued for posttransplant immunosuppression. Over the next 3 days, her mental status continued to worsen in the setting of acute hyponatremia (nadir 121) and uncontrolled hypertension (BP 164/98 immediately preceding seizure, range 133/ 92-249/152, average $168 / 109 \mathrm{~mm} \mathrm{Hg}$ from admission to 12 hours postseizure). Repeat CT head did not show hydrocephalus. Repeat MRI showed worsening T2 FLAIR changes now involving the posterior parietal regions, as well as bilateral thalami. With strict hypertension control (average BP $137 / 83 \mathrm{~mm} \mathrm{Hg}$ ), her mental status slowly returned to baseline. Nine days after acute presentation, she was awake, alert, and oriented to self, with strength and sensation intact, increased tone in the left compared to the right, and brisk left patellar and brachioradialis reflexes. She was discharged to a rehabilitation center and has not had recurrent episodes of PRES in the last year since her immunosuppression was changed to everolimus, prednisone, and belatacept. Follow-up MRI (figure 1, I-L) 1 year after the initial presentation of PRES demonstrated resolution of most of the T2 FLAIR abnormalities except for those in the superior parietal and left posterior frontal regions. She continued to have mild cognitive deficits following resolution of her other neurologic symptoms.

\section{Discussion}

PRES presents classically with altered mental status (50\%-80\%), headaches (50\%), seizures (60\%-75\%), and visual disturbances (33\%). ${ }^{1,2}$ On MRI, one often sees vasogenic edema bilaterally in parieto-occipital and posterior frontal cortical and subcortical white matter. A subset of patients may present with focal infarcts (10\%-25\% of cases) or intracranial hemorrhage (10\%-15\% of cases). ${ }^{3}$ Restricted diffusion representing cytotoxic edema can occur in atypical cases. This may progress to infarction with residual deficits, often reversible. ${ }^{4}$ The exact mechanism of this cytotoxic edema is unknown. Death occurs in fewer than $10 \%$ of diagnosed cases; the mortality among undiagnosed cases is unknown but may be due to increased tissue pressure, localized blood vessel compression, and subsequent ischemia. Atypical presentations of PRES are increasingly being reported, with the majority of cases describing a central pattern with edema noted within the brainstem, basal ganglia, or cerebellum. ${ }^{3,5}$ The edema is often bilateral, but occasional rare cases have noted a unilateral appearance. Edema in these locations has been associated with life-threatening acute hydrocephalus secondary to compression of the fourth ventricle in rare case reports. ${ }^{6}$

PRES is often associated with severe, acute hypertension, with only $10 \%-30 \%$ of patients with PRES having normal or mildly elevated BP. ${ }^{4,7}$ PRES can also result from drug exposure, especially immunosuppressing agents (tacrolimus, cyclosporine). ${ }^{4,7,8}$ Overall incidence of PRES in transplant patients on tacrolimus varies from $0.49 \%$ up to $6 \%$ in older studies and often develops in the first 12 months of treatment. $^{8}$ The pathophysiology behind medication-induced PRES is not well-understood but believed to be similar to the potential mechanisms of hypertensive PRES, including local breakdown of the blood-brain barrier secondary to hyperperfusion causing extravasation of blood and subsequent localized cerebral edema ${ }^{3}$ and endothelial dysfunction secondary to the direct effects of the immunosuppressant causing vasospasm and brain hypoperfusion. ${ }^{8}$ Calcineurin inhibitors may specifically lead to higher rates of PRES compared to other immunosuppressant medications due to treatment-associated hypertension, disruption of the bloodbrain barrier through vasoconstriction, toxic effects on neurons and oligodendrocytes, and changes in neural transmission. ${ }^{9}$ Management of PRES in this case involves removal of the offending medication, management of hypertension if present, and supportive care in the intensive care unit. In the case of immunosuppressants as the cause, changing to a medication with an alternative mechanism of action, such as mTOR inhibitors (everolimus, sirolimus), glucocorticoids, or mycophenolate mofetil (reversible inhibitor of inosine-5'-monophosphate dehydrogenase in guanosine nucleotide synthesis), is a viable option. ${ }^{4,9}$ Corticosteroids can hypothetically be used to decrease vasogenic edema and serve as an alternative immunosuppressant. ${ }^{7}$ In cases presenting with acute hydrocephalus, ventricular drainage (temporary or permanent) or posterior fossa decompression in the setting of severe cerebellar edema may be indicated. ${ }^{6}$ This patient's case describes the importance of recognizing PRES, providing the appropriate supportive treatment, and treating associated complications such as seizures and hydrocephalus promptly to avoid a potentially catastrophic neurologic outcome. 


\section{Author contributions}

C. Catherine: case concept and design, critical revision of manuscript for intellectual content. C. Yanta: critical revision of manuscript for intellectual content. A. Saand: critical revision of manuscript for intellectual content. M. Pilato: critical revision of manuscript for intellectual content. S.H.-Y. Chou: case concept and design, critical revision of manuscript for intellectual content.

\section{Study funding}

No targeted funding reported.

\section{Disclosure}

C. Catherine, C. Yanta, A. Saand, and M. Pilato report no disclosures relevant to the manuscript. S.H.-Y. Chou is funded by the NIH NINDS K23 award, University of Pittsburgh Development grant, and University of Pittsburgh Physicians Foundation Award, and served as site principal investigator for the NEWTON 2 trial on behalf of Edge Therapeutics. Dr. Chou performed ad hoc consulting services for Edge
Therapeutics and Merck Co. Go to Neurology.org/ $\mathrm{N}$ for full disclosures.

\section{References}

1. Fugate JE, Claassen DO, Cloft HJ, Kallmes DF, Kozak OS, Rabinstein AA. Posterior reversible encephalopathy syndrome: associated clinical and radiologic findings. Mayo Clin Proc 2010;85:427-432.

2. Grioni D, Rovelli A, Pavan F, Prunotto G. The diagnosis of posterior reversible encephalopathy syndrome. Lancet Neurol 2015;14:1073-1074.

3. McKinney AM, Short J, Truwitt CL, et al. Posterior reversible encephalopathy syndrome: incidence of atypical regions of involvement and imaging findings. AJR 2007; 189:904-912.

4. Barbas AS, Rege AS, Castleberry AW, et al. Posterior reversible encephalopathy syndrome independently associated with tacrolimus and sirolimus after multivisceral transplantation. Am J Transplant 2013;13:808-810.

5. Stevens CJ, Heran MKS. The many faces of posterior reversible encephalopathy syndrome. Br J Radiol 2012;85:1566-1575.

6. Grossbach AJ, Abel TJ, Hodis B, Wassef SN, Greenlee JD. Hypertensive posterior reversible encephalopathy syndrome causing posterior fossa edema and hydrocephalus. J Clin Neurosci 2014;21:207-211.

7. Hobson EV, Craven I, Blank SC. Posterior reversible encephalopathy syndrome: a truly treatable neurologic illness. Perit Dial Int 2012;32:590-594.

8. Wu Q, Marescaus C, Wolff V, et al. Tacrolimus-associated posterior reversible encephalopathy syndrome after solid organ transplantation. Eur Neurol 2010;64: 169-177.

9. Pustavoitau A, Bhardwaj A, Stevens R. Neurological complications of transplantation. J Intens Care Med 2011;26:209-222. 


\section{Neurology}

\section{Pearls \& Oy-sters: The dangers of PRES: An atypical case with life-threatening presentation \\ Christina Catherine, Claire Yanta, Aisha R. Saand, et al. \\ Neurology 2019;92;e282-e285 \\ DOI 10.1212/WNL.0000000000006775}

\section{This information is current as of January 14, 2019}

\section{Updated Information \& Services}

References

Subspecialty Collections

Permissions \& Licensing

Reprints including high resolution figures, can be found at: http://n.neurology.org/content/92/3/e282.full

This article cites 9 articles, 2 of which you can access for free at: http://n.neurology.org/content/92/3/e282.full\#ref-list-1

This article, along with others on similar topics, appears in the following collection(s):

Critical care

http://n.neurology.org/cgi/collection/critical_care

MRI

http://n.neurology.org/cgi/collection/mri

Other toxicology

http://n.neurology.org/cgi/collection/other_toxicology

Information about reproducing this article in parts (figures,tables) or in its entirety can be found online at:

http://www.neurology.org/about/about_the_journal\#permissions

Information about ordering reprints can be found online:

http://n.neurology.org/subscribers/advertise

Neurology ${ }^{\circledR}$ is the official journal of the American Academy of Neurology. Published continuously since 1951, it is now a weekly with 48 issues per year. Copyright (O 2019 American Academy of Neurology. All rights reserved. Print ISSN: 0028-3878. Online ISSN: 1526-632X.

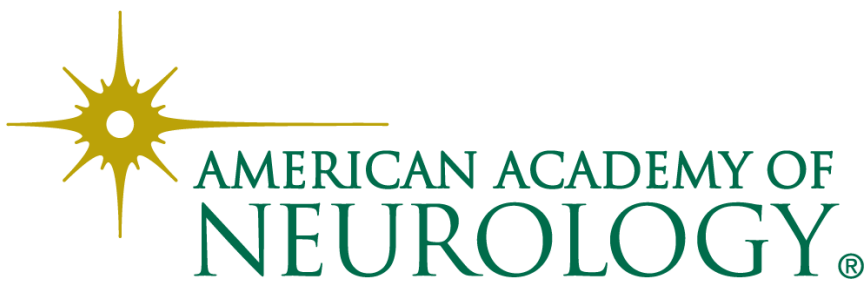

